\title{
Simplified Scheduling of a Building Construction Process using Discrete Event Simulation
}

Eric Forcael, Ph.D. ${ }^{1}$, Marcelo González, P.E. ${ }^{1}$, Jaime Soto, M.Sc. ${ }^{1}$, Francisco Ramis, Ph.D. ${ }^{1}$, and Carlos Rodríguez, Ph.D. ${ }^{2}$

${ }^{1}$ Universidad del Bío-Bío, Chile, eforcael@ubiobio.cl,mgonzval@alumnos.ubiobio.cl,jsotom@ubiobio.cl, framis@ubiobio.cl

${ }^{2}$ Escuela Superior Politécnica del Litoral, Ecuador, crodrigu@espol.edu.ec

\begin{abstract}
Planning and Scheduling tools used by construction professionals nowadays not always consider the effect of variability in the construction process; they do not consider explicitly the effect of changes in activity durations along the production chain. Discrete event simulation approach is a relevant exception that deserves particular attention from the construction industry. The present research proposes a discrete event simulation model applied to a simplified construction process schedule. This model considered main construction activities divided in: foundations, structure and roofing. The model can be extended and easily applied to other construction activities. Input parameters for the model were obtained directly from on-site field experience and a beta unimodal distribution assigned. On a first stage, PERT scheduling methodology was used for the model, which was later compared with discrete event simulation. Results did not provide evidence of significant statistical differences between different probability distribution used with respect to the mean project duration obtained using PERT scheduling as compared to the discrete event simulation model. This provides conclusions about total project duration and validation of the probability distribution types considered in the present research.

Keywords- Simplified Scheduling, Building Construction, Discrete Event Simulation, PERT
\end{abstract}

Digital Object Identifier (DOI):http://dx.doi.org/10.18687/LACCEI2018.1.1.194 ISBN: 978-0-9993443-1-6

ISSN: $2414-6390$

16 $^{\text {th }}$ LACCEI International Multi-Conference for Engineering, Education, and Technology: "Innovation in Education and Inclusion”, 19-21 July 2018, Lima, Peru. 


\title{
Simplified Scheduling of a Building Construction Process using Discrete Event Simulation
}

\author{
Eric Forcael, Ph.D. ${ }^{1}$, Marcelo González, P.E. ${ }^{1}$, Jaime Soto, M.Sc. ${ }^{1}$, Francisco Ramis, Ph.D. ${ }^{1}$, and Carlos Rodríguez, \\ Ph.D. ${ }^{2}$ \\ 1'Universidad del Bío-Bío,Chile, eforcael@ubiobio.cl,mgonzval@alumnos.ubiobio.cl,jsotom@ubiobio.cl, framis@ubiobio.cl \\ ${ }^{2}$ Escuela Superior Politécnica del Litoral, Ecuador, crodrigu@espol.edu.ec
}

\begin{abstract}
Planning and Scheduling tools used by construction professionals nowadays not always consider the effect of variability in the construction process; they do not consider explicitly the effect of changes in activity durations along the production chain. Discrete event simulation approach is a relevant exception that deserves particular attention from the construction industry. The present research proposes a discrete event simulation model applied to a simplified construction process schedule. This model considered main construction activities divided in: foundations, structure and roofing. The model can be extended and easily applied to other construction activities. Input parameters for the model were obtained directly from on-site field experience and a beta unimodal distribution assigned. On a first stage, PERT scheduling methodology was used for the model, which was later compared with discrete event simulation. Results did not provide evidence of significant statistical differences between different probability distribution used with respect to the mean project duration obtained using PERT scheduling as compared to the discrete event simulation model. This provides conclusions about total project duration and validation of the probability distribution types considered in the present research.
\end{abstract}

Keywords-- Simplified Scheduling; Building Construction; Discrete Event Simulation; PERT.

\section{INTRODUCTION}

Construction projects are regularly exposed to problems related to the planning and execution of works, product of imprecise scheduling and inadequate allocation of roles and resources. As a result of this, it has been necessary to implement new approaches in the construction management processes, in order to minimize project duration delay, one of these approaches being the Discrete Event Simulation [1], [2].

Accordingly, the present research consists of developing a discrete event simulation model applied to a building process by means of a simplified scheduling model, capable of incorporating the dynamics of constructive processes through a stochastic analysis of construction activities.

The construction industry represents a considerable contribution to the Gross Domestic Product of national economies, but despite its importance, the construction industry faces a characteristic problem; the existence of lags or delays in production processes. It is usual that construction projects do not meet the scheduled total duration and exceed the budgeted costs [3].

On the other hand, due to the inherent nature of the construction industry, all projects have a certain amount and type of associated uncertainty $[4,5]$. The complexity and uncertainty of a construction project produces variability in

Digital Object Identifier (DOI): http://dx.doi.org/10.18687/LACCEI2018.1.1.194 ISBN: 978-0-9993443-1-6

ISSN: 2414-6390 production flows, in detriment of the performance of a productive system $[6,7]$. Understanding the variability as the quality of non-uniformity of a type of entity, this has been a subject of study due to its close relationship with the randomness of a phenomenon, where the Discrete Events Simulation has demonstrated for many years the ability to address such effect $[8,9]$.

Moreover, the current construction scheduling techniques have not efficiently tackled the inconstant nature of the construction processes, especially the uncertainty related to the duration necessary to complete an activity. This type of random variation, known as natural variability (fluctuation due to differences between operators, machines and materials), random detentions due to climatic conditions, preparations, availability of labor and work redone (due to unacceptable quality) has not been incorporated in a massive way and simplified in the traditional schemes of construction process scheduling. The common practice of the construction professionals has been to assign activities durations under a static or deterministic approach, which does not represent the reality of the construction projects.

\section{LITERATURE REVIEW}

\section{A. Simulation}

On 1948, with the contributions of Harris and Kahn, begins the study of simulation as a field of knowledge, where they systematized the first simulation techniques that were applied in different environments [10].

Then, Banks et al. [11] defines simulation as the digital implementation of a dynamic model through time, which generates an artificial history of modeled systems, where the contemporary concept of simulation arose from the evolution of the Monte Carlo method and applications of statistical, physical and mathematical models, as a consequence of the development of computer tools [12].

Since then many authors have based the study of simulation considering it an art based on intuition $[13,14,15]$. This conception implies that the modeling process is developed by a select and trained group of creative people, although other researchers have also considered the exercise of simulation as a technical solution or as a combination of art and science $[16,17]$.

Since the $70 \mathrm{~s}$, simulation has been increasing attention due to the growing acceptance of the different disciplines of science and its varied applications in the military industry, production and services. Its widespread use, as a consequence

$1^{\text {th }}$ LACCEI International Multi-Conference for Engineering, Education, and Technology: "Innovation in Education and

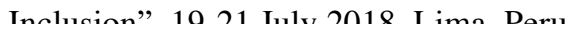


of the evolution of computer science, has led from then until now to be practiced in various knowledge areas and disciplines [18, 19, 1].

\section{B. Simulation in Engineering}

One of the first engineering simulation practices dates back to the 1920s and 1930s, when statisticians began using the first machines and random number tables to develop and understand statistical theory [20].

As long as computational simulation costs decrease since the $70 \mathrm{~s}$, and in parallel with the evolution of a series of general-purpose computer tools, such as FORTRAN, C ++ \& Visual Basic, the simulation began to be used by a number of organizations, especially by industrial engineering and operations research [21]. This accompanied by the appearance of new special purpose software and data packages (Arena, Extend, Simscrip, ProModel, FlexSim, etc.), led the simulation to expand to various areas, such as chemical engineering [22], electrical engineering [23], mechanical engineering and automation [24], among many others.

Due to the computational potential of the software tools and software available to engineers today, the use and dependence of simulation has increased throughout the engineering design process [25]. In this sense, there are multiple instances where the simulation has landed in the engineering community where, for example, the Winter Simulation Conference is currently an international benchmark in demonstrating the advances in engineering simulation, grouping year after year the maximum exponents in this matter [26].

\section{Simulation in Civil Engineering}

One of the first experiences with computer simulations in Civil Engineering had its origin in 1979. A group of researchers, members of the Civil Engineering Department of the University of Nottingham, conducted a study over a 10 years period, with the objective to observe and measure the results that the implementation of this type of tools would take in the teaching-learning process of their students [27]. The results concluded that students benefited from the use of these computational tools, adopting them to solve and understand problems in relevant areas of the profession, such as planning and control of construction and negotiation projects within the construction process.

Since the adoption of simulation experiences in the classroom, this has brought multiple benefits and a variety of uses and applications in Civil Engineering [28]. In particular regarding the ways in which tools are conveyed to students to create and review construction schedules, and disseminate through simulations the knowledge based on the Lean Construction philosophy [29, 30].

Finally, a series of other investigations on simulation in civil engineering, related to areas of project management [31], earthworks [32], tunnels [33, 34, 35], hydraulic design and water systems [36], structures [2, 37], among others, stand out.
Most of these applications have been mainly intended to deal with the complexity of the problems in which an analytical solution is not feasible.

\section{Construction Simulation}

The first application of simulation to constructive processes was directed by Halpin in 1977, with the introduction of CYCLONE (CYCLic Operations Network), simulation tool created to model, analyze and control operations in construction of repetitive character [38]. The modeling implemented by Halpin prompted the emergence of a series of simulation research and methodologies applied to the construction sector.

At the beginning of the $90 \mathrm{~s}$, with the advent of objectoriented programming languages, a series of research and applications aimed at these languages in construction began [39]. It was thus during that decade the most recognized software flourished, such as: COOPS; COST; Myclocyclone; CIPROS; Disco; and STROBOSCOPE-CPM.

To the extent that new and more powerful programming languages and computing tools were developed, the ability to solve increasingly complex problems in construction was also developed. With the introduction and advances in terms of what is known as Special Purpose Simulation Approaches [40], progress was made in the generation of specific simulation environments, seeking to reach professionals of the construction industry with little or no experience in the theory of simulation [41, 42].

In the 2000 s, 3D visualization systems allowed describing simulation processes in a more intuitive and friendly way [43]. Later, with the advent of more specialized software in construction processes, it was possible to get closer to real systems [44].

Thus, in recent years, applications and research in construction management has experienced significant academic growth [32]; where the current state has resulted in an increased tendency to apply simulation tools to construction projects of different nature [45]. On the other hand, the combination of $3 \mathrm{D}$ models with construction schedules to create models in four dimensions (4D), has allowed visualizing work progress in real time [46, 42]. Accordingly, numerous investigations involving Building Information Models (BIM) have proliferated as a revolutionary strategy for the integration of large-scale construction projects.

Notwithstanding the aforementioned, although there are extensive investigations regarding simulations that involve construction schedules; these continue to be complex to be applied by professionals who have little or no experience with modeling. That being said, there is limited evidence of a simplified method of scheduling construction activities, based on valid Discrete Event Simulation, which allows any construction professional create, in a simple way, their own models and extend them to any construction project; realizing the main objective of this paper.

$16^{\text {th }}$ LACCEI International Multi-Conference for Engineering, Education, and Technology: "Innovation in Education and 


\section{METHODOLOGY}

This study proposes the use of a Discrete Events Simulation (DES) model as a valid and extensible tool in the simplified scheduling of a construction project. For this prupose, the analysis consisted of simulating main construction activities, taking as a case study a dwelling unit, and then comparing the construction durations of the simulated project, with the durations delivered by a traditional scheduling method, elaborated based on PERT (Program Evaluation and Review Technique) methodology.

The constructive operation for simplicity was divided into 3 activities considered as critical activities corresponding to: Foundations, Structure and Roofing. In a first stage, the construction system was simulated using a PERT scheduling model, using input parameters collected on field. In parallel, a Discrete Event Simulation model was formulated, which was subsequently implemented through the FlexSim ${ }^{\mathrm{TM}}$ computational tool.

Finally, to validate this new simplified scheduling approach, based on Discrete Simulation, a statistical contrast was made between both models (PERT \& DES), in order to compare both expected durations of the constructive process. The methodology used is summarized in Figure 1.

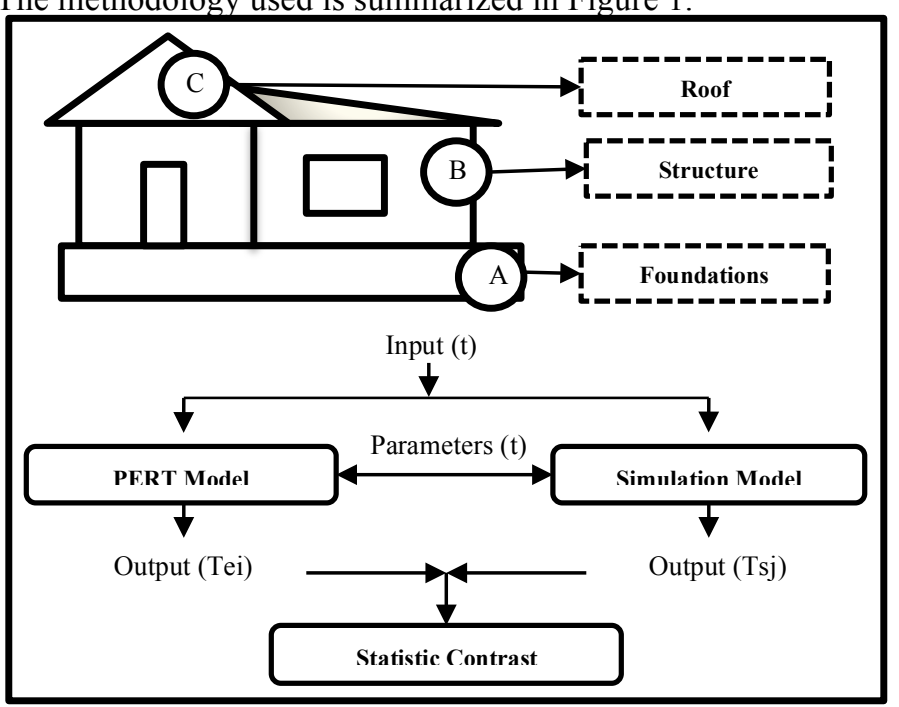

Fig. 1 Methodology used for the study case.

\section{SCHEDULING USING PERT}

The PERT method is a scheduling technique that considers the non-deterministic condition of activities durations involved in a project [47]. This method is derived from the conventional network model CPM (Critical Path Method), with the difference that PERT allows managing the uncertainty of the activities, assuming a type of statistical distribution. For years, CPM \& PERT have proven to be useful tools for planning, scheduling and controlling construction projects [48].

PERT considers the beta distribution as an adequate distribution for the calculation of the duration of an activity. Due to its flexibility to adapt in situations in which the absence of specific data, with respect to the durations of the activities measured in situ, do not prevent having a global idea of the statistical behavior of the expected durations of execution of the activities, taking as a single reference the experienced in the field [49].

The PERT method maintains that the construction duration of the activities is obtained through the estimation of 3 possible subjective scenarios:

1) Optimistic duration (a): Minimum possible duration that is necessary to carry out an activity.

2) Most probable duration $(m)$ : It is the best estimate of the duration necessary to carry out an activity, assuming normal conditions.

3) Pessimistic duration (b): Maximum duration to carry out an activity, assuming unfavorable conditions.

Under these estimates ( $a, m$ and $b$ ) and based on the unimodal beta distribution, it is possible to determine an expected duration of an activity (Ed Act.), that will sum the average value of the three estimates with a given weight. The PERT method suggests eminently practical expressions of the average duration of an activity (equation 1) and its corresponding variance (equation 2) [50].

$$
\begin{aligned}
\text { Ed Act. } & =\frac{(a+4 m+b)}{6} \\
S^{2} & =\frac{(b-a)^{2}}{6}
\end{aligned}
$$

The procedure used to build the PERT model was as follows:

- The respective activities and durations were identified.

- The appropriate sequences were determined for each activity. - The PERT network diagram was built.

- Finally, the expected duration for each of the activities involved (Ed Act.) were calculated.

As mentioned before, the study case was divided into 3 construction activities, ordered sequentially as follows: Foundations, Structure and Roofing. Assuming that the estimated durations collected on site are sufficiently precise, due to the familiarity of the experts consulted with the objective activities it was possible to obtain construction duration of the activities in their optimistic, more probable and pessimistic scenarios (durations a, $\mathrm{m}$ and $\mathrm{b}$ respectively).

The durations were translated to a table where the precedences and nomenclatures of the activities were defined. Because it is a sequential model, in order to start a certain activity, the completion of a single previous activity is necessary; the network diagram was built linearly and from left to right, as shown in Figure 2. Finally, the total construction expected duration (Tep), corresponded to the sum of the average durations expected in the critical path ( $\Sigma$ Tecr), corresponding to the 3 activities under analysis [50]. 


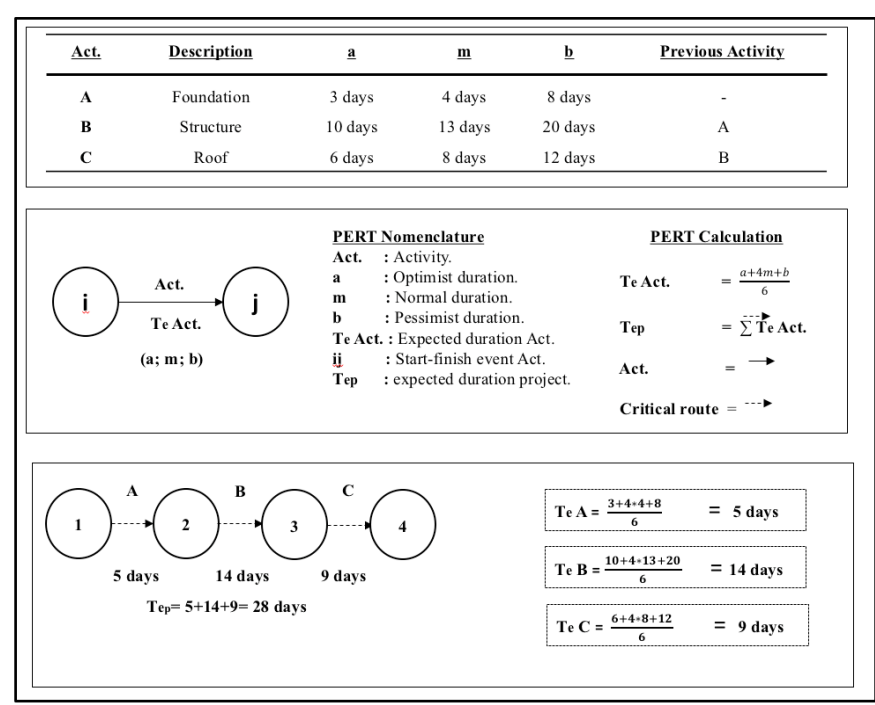

Fig. 2. PERT network model for the considered case study.

\section{SCHEDULING USING DisCRETE EVENT SimULATION}

Most simulation models in construction can be treated as stochastic models [51], which are defined as the system that has a random behavior; i.e., for known system inputs, it is not possible to guarantee the output values [21]. In other words, the functional relationships between the system variables are not perfectly defined as in the case of a deterministic model, but can be modeled under a certain probabilistic behavior and within a limited or discrete duration range.

During the last three decades, Discrete Event Simulation techniques have been used to provide reliable solutions for risky scheduling of construction projects, demonstrating an impetus in their ability to explain complex problems, in particular of dynamic and iterative operations [52].

The steps used to develop the scheduling model, based on discrete simulation, consisted of a definition of the constructive system, formulation, implementation and validation of the system, finally performing the corresponding analysis of results.

\section{A. System definition}

Looking at a construction project as a production cycle has been a key point since the first meeting of the International Group of Lean Construction in 1993, where the Lean philosophy was adopted, with the fundamental purpose of eliminating the process (or minimizing the impact) of activities that do not add value [45]. Although the conception of the productive systems in the construction industry, and in the manufacturing industry, start from the same global characterization, given by the sequence inputs-transformationresult, the construction industry presents characteristics of structure and flow that suggest differences with the manufacturing industry [53]. These can be classified as: (a) the product is unique in its type; (b) the product is produced at the site where it will operate; (c) a temporary organization is established and; (d) has a strong regulatory intervention.
This way, identifying a production system under construction, implies recognizing its input-process-exit elements [54]. Thus, the simulation model was constructed on the basis of the problem under study, considering it as a production system, with a flow of entities throughout the processes, as can be seen in the general scheme of Figure 3. Understanding that the processes under construction transform the flows of entities into finished or semi-finished products [55]; the entities were defined as the products of their processes.

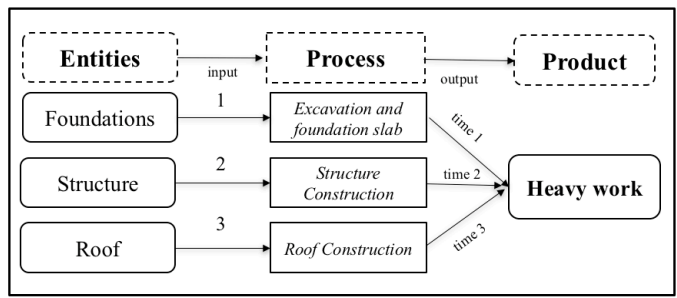

Fig. 3. General scheme of the simulation model.

\section{B. Simulation model formulation}

1) Algorithm and Pseudocode: to represent the simplicity of the system to be simulated, the algorithm and pseudocode outlined in Figure 5 were designed. First, the entities were declared as input through a numeric value, in such a way that this attribute would consider the logical sequence of the constructive process. The inclusion of the entities was configured through a For cycle; in charge of programming the release and processing of the entities to the work stations through a counter (Cont). Finally, a beta distribution with parameters of minimum and maximum duration was assigned for each input independently for each activity.

2) Model hypothesis: Once the conceptual model of the construction system was formulated, the basic hypotheses that would characterize and govern the production system had to be established, for its subsequent implementation. The hypotheses were the following: a) Entities or production units pass through the product, unlike in a manufacturing model (entities in finished state); b) Activities can be started and completed independently within a specific sequence (it is generally assumed that there are sufficient resources available to perform the necessary work).

\section{Model implementation}

In order to simply reproduce the behavior of the construction system, the simulation model was developed using FlexSim ${ }^{\mathrm{TM}}$ software, due to its flexible environment and user-friendly interface.

Entities were declared and configured by applying a label (1, 2 and 3 for each activity respectively). This attribute programmed the release of the entities in their finished states (Input) to the work stations (Processors), with the purpose that once an activity was processed immediately afterwards, the next one (programming in Source objects), avoiding phase shifts Waits or lack of resources. Figure 4 shows the implementation of the developed production model. 
1) Discrete probability functions assignment: As in the PERT method, the durations were assigned a beta distribution with minimum and maximum duration parameters (corresponding to durations $a$ and $b$ respectively of the PERT method). Figure 6 shows the configuration of the probability functions linked to each of the activities scheduled in FlexSim ${ }^{\mathrm{TM}}$.

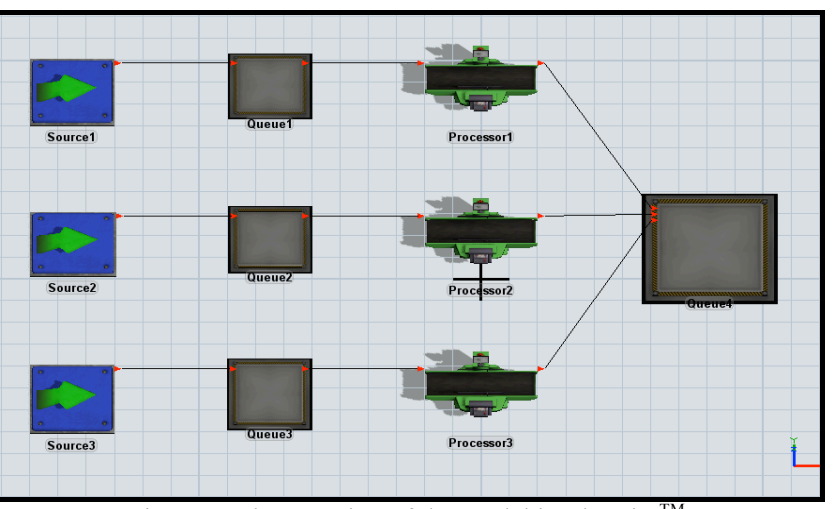

Fig. 4. Implementation of the model in FlexSim ${ }^{\mathrm{TM}}$.

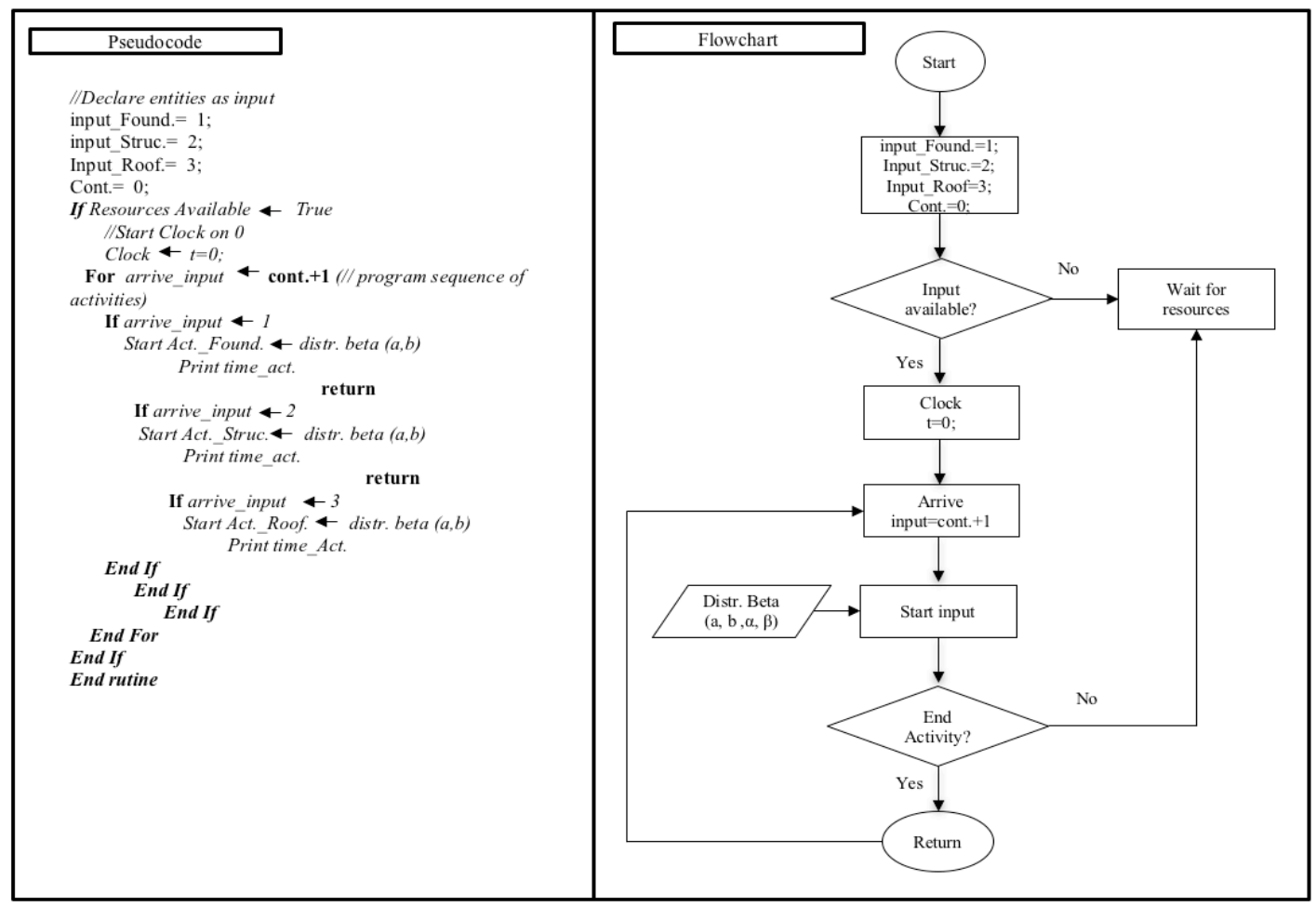

Fig. 5. Flow diagram and Pseudocode in the construction of the simulation model. 


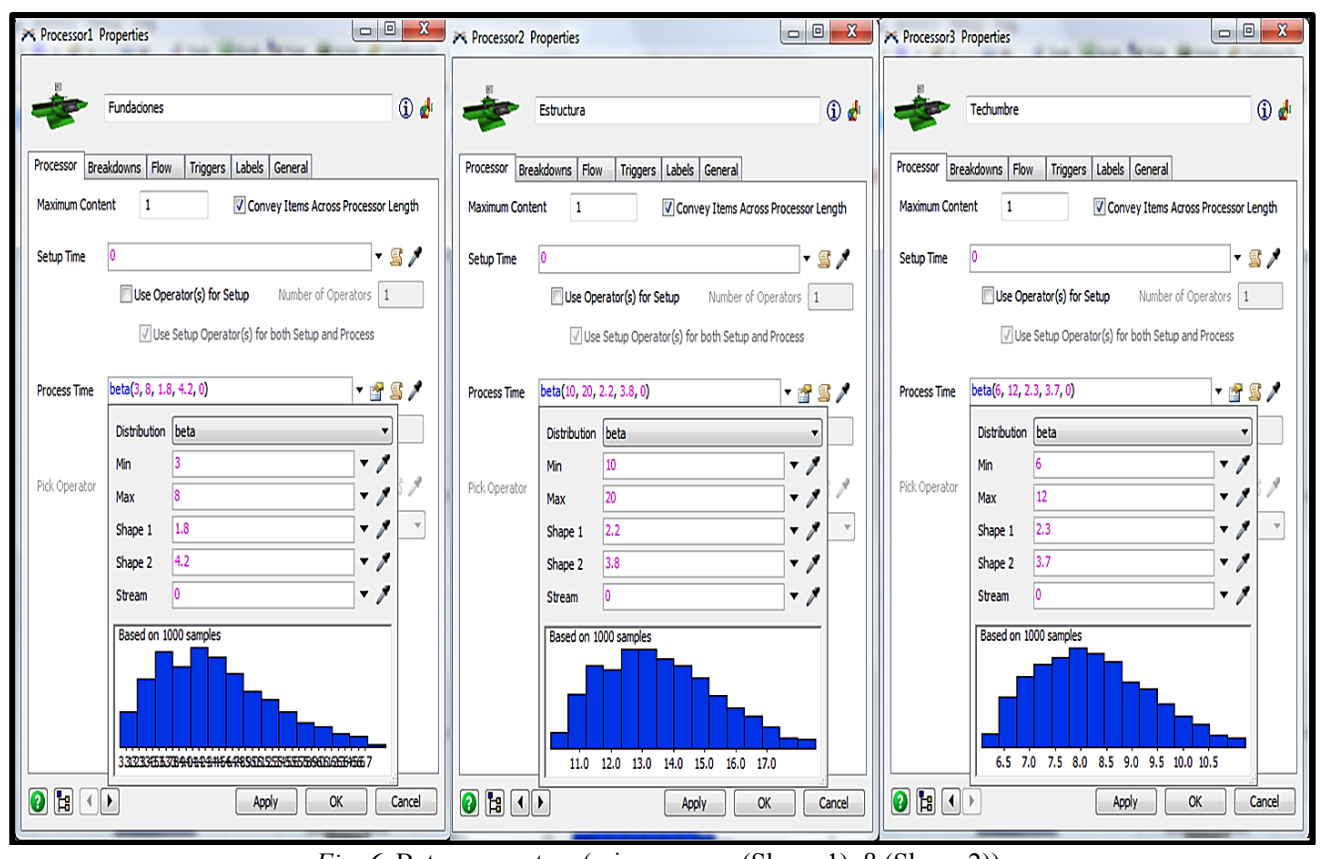

Fig. 6. Beta parameters (min., max, $\alpha$ (Shape 1), $\beta$ (Shape 2)).

2) Beta parameters $\alpha$ and $\beta$ : The parameters $\alpha$ and $\beta$ used for the assignment of a probability function to the simulation model were obtained from the expected average durations associated with the distributions of the activities (Te Act.), the most probable m-value, the maximum a of the minimum $b$, these durations being taken from the PERT model (Figure 2) and linked to the estimation of the shape parameters ( $\alpha$ and $\beta$ ) by means of equations 3 and 4 [56].

$$
\begin{gathered}
\alpha=\frac{(T e \text { Act. }-a)(2 m-a-b)}{(m-T e \text { Act. })(b-a)} \\
\beta=\frac{(b-T e \text { Act. })}{(\text { Te Act.-a) }} \alpha
\end{gathered}
$$

\section{SimUlation MODEL VALIDATION}

To statistically validate the average duration of the simulation model $\left(\mathrm{Ts}_{\mathrm{m}}\right)$ the confidence interval methodology was used. This methodology establishes that according to a specific precision or tolerated by the modeler $\left(\varepsilon_{i}\right)$, the average length of a confidence interval $\mathrm{H}$, corresponding to the difference between the average duration of the simulation model $T s_{\mathrm{m}}$ and a certain arbitrary error $\left(\varepsilon_{\mathrm{i}}\right)$, which for a given confidence level of $100(1-\alpha) \%$ and based on the student $t$ distribution, is determined by equation 5 .

$$
H=T s_{m}-\varepsilon_{i}=t_{\alpha / 2 ; n-1} \frac{S o}{\sqrt{n}}
$$

Where,

$H$ : Average length of confidence interval.

$n$ : Number of replicates for a desired level of accuracy.

$S_{o}$ : Standard deviation of the pilot sample.

$t_{\alpha / 2, n-1}$ : Critical value of $\alpha / 2$ corresponding to $95 \%$ of the student $t$ distribution.
In order to meet a certain precision, we had to find a number of replicas $\mathrm{n}$, such that it was greater than or equal to $n_{0}$, with $n_{0}$ as the first replica that would satisfy a certain $\varepsilon_{i}$. Arbitrarily, an $\varepsilon_{i}$ of 0.5 days was assumed for the analysis of each of the activities, according to equation 6 .

$$
H=t_{\alpha / 2 ; n-1} \frac{S o}{\sqrt{n}} \leq \varepsilon_{i} \leq 0.5 \text { days }
$$

\section{A. Calculation of the number of replicas}

The number of replicates $n$ to obtain the average duration of the simulation model Tsm was calculated independently for each of the activities involved in the construction process. The procedure was iterative according to equation 6 and to the critical values of the t-student distribution, as shown in Table 1. The standard deviation of the pilot samples $\left(S_{0}\right)$ that was used for each of the activities was calculated from the variance analyzed by PERT simulation (equation 2).

TABLE I

ITERATIVE PROCESS TO FIND N NUMBER OF REPLICAS

\begin{tabular}{|cc|c|}
\hline$n_{0}$ & $t_{\alpha / 2 ;} n_{l-1} \frac{s 0}{\sqrt{n 0}}$ & $\varepsilon_{0}$ \\
\hline$n_{l}$ & $t_{\alpha / 2 ;} n_{2-1} \frac{s 0}{\sqrt{n_{2}}}$ & $\varepsilon_{l}$ \\
\hline$\vdots$ & $\vdots$ & $\vdots$ \\
\hline$n$ & $t_{\alpha / 2 ;} n_{n-1} \frac{s 0}{\sqrt{n_{n}}}$ & $\varepsilon_{i}=0.5$ days \\
\hline
\end{tabular}

In order for the average durations of the activities in the simulation model $\left(\mathrm{Ts}_{\mathrm{m}}\right)$ to stabilize, it was necessary that the number of replicas be accurate enough not to defer from the admitted precision $(0.5$ days $)$. Figure 7 summarizes the 
evolution of the behavior of the precision of the simulation model $\left(\varepsilon_{i}\right)$, as the number $\mathrm{n}$ of replicas increased, until reaching the minimum desired error $\varepsilon_{i}$ of 0.5 days.

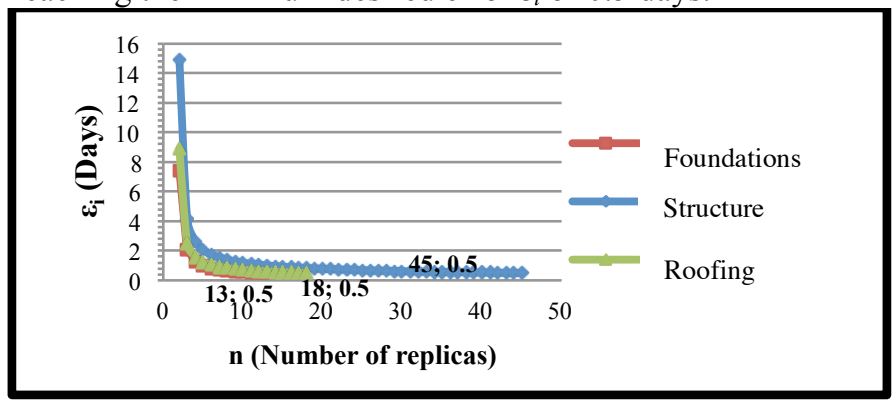

Fig. 7. Evolution of the error ( $\varepsilon i$ ) to find the number $n$ of replicas.

\section{B. Simulation and convergence analysis}

The simulation stage was carried out under the assumption that the simulation model did not contemplate a period of warming or suppression of initial data, because it emulates a real construction project, which begins its work at the beginning of the production chain, without units of work in time 0 [21].

Considering this hypothesis, the model was run according to the number of replicas shown in Figure 1. From the software, the random durations of each of the activities of the simulation model $\left(\mathrm{Ts}_{\mathrm{j}}\right)$, were captured, where the convergence behavior of the mean durations $\left(\mathrm{Ts}_{\mathrm{m}}\right)$, for each activity independently.

The evolution of the average durations of the simulation model $\left(\mathrm{Ts}_{\mathrm{m}}\right)$, for a number of replications $\mathrm{n}$ and tolerated error of 0.5 days, is presented in Figure 8. In this graph it can be observed that the behavior of the average durations of the simulation model, it was adjusted from a transient state to a stable state. The samples $n$ of the model's exit $\left(T s_{\mathrm{mj}}\right)$ began with an initial transition period (run in), with average durations $\left(T \mathrm{~s}_{\mathrm{m}}\right)$ distant or very distant to converge to a specific average duration (biased data); however, to the extent that the number of samples $\mathrm{n}$ increased, the random variable $\mathrm{Ts}_{\mathrm{mj}}$ reached a stable state. The explanation is that the initial conditions determine an initial bias, which influences the average time at which the steady state is reached.

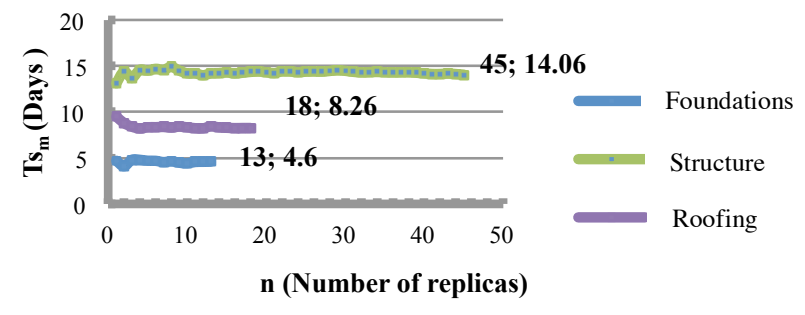

Fig. 8. Convergence of mean durations (Tsm) versus number of replicas (n).

\section{Average duration of the simulation model}

The mean durations of activities of the simulation model $\left(T s_{m}\right)$, were obtained by calculating the confidence intervals independently by activity, and considering a confidence level of $95 \%$ for the average duration, using equation 7 .

$$
\overline{\mathrm{Y}} \pm t_{\frac{\boldsymbol{\alpha}}{2} ; n-1}\left(\frac{S o}{\sqrt{n}}\right)
$$

The classical interpretation of confidence intervals is that, in repeated samples (n), these will contain the average duration of the population; along with the standard deviation from which the samples were taken [57]. In practical terms, it can be established, with $95 \%$ confidence, that the average duration of construction of each of the activities (Foundations, Structure and Roofing) was found somewhere between these 2 intervals (equation 7).

Table 2 shows the average durations of the simulation model and the detail of the confidence intervals associated with each of the activities.

As in the PERT simulation model, the assumption made was that the total duration of the project would correspond to the sum of the expected durations of the activities ( $\sum$ Te Act.). Similarly, the duration or average duration of the simulation model in the construction process of gross work $\left(\mathrm{Ts}_{\mathrm{mp}}\right)$ corresponded to the sum of the expected average duration of execution of the activities $\left(\sum \mathrm{Ts}_{\mathrm{m}}\right)$, approximating the average durations to the next largest number entire duration, as a most unfavorable condition.

TABLE II

AVERAGE DURATIONS OF THE ACTIVITIES IN THE SIMULATION MODEL

\begin{tabular}{|l|c|c|c|c|c|}
\hline \multicolumn{1}{|c|}{ Activity } & $\begin{array}{c}\boldsymbol{n} \\
\text { (Days) }\end{array}$ & $\begin{array}{c}\boldsymbol{S} \\
\text { (Days) }\end{array}$ & $\overline{\mathbf{Y}} \pm \mathbf{t} \mathbf{\alpha} / \mathbf{2} ; \mathbf{n}-\mathbf{1} \frac{\mathbf{s}}{\sqrt{\mathbf{n}}}$ & $\begin{array}{c}\boldsymbol{T s}_{\boldsymbol{m}} \\
\text { (Days) }\end{array}$ & $\begin{array}{c}\text { Approx. } \\
\text { longest } \\
\text { entire } \\
\text { duration }\end{array}$ \\
\hline Foundations & 13 & 0.89 & $4.06<4.6<5.13$ & 4.6 & 5 \\
\hline Structure & 45 & 1.95 & $13.47<14.06<14.65$ & 14.00 & 14 \\
\hline Roofing & 18 & 1 & $7.76<8.26<8.75$ & 8.26 & 9 \\
\hline \multicolumn{1}{|c|}{ Ts $_{\text {mp }}$} & - & $\mathbf{4}$ & - & $\mathbf{2 6 , 9 2}$ & $\mathbf{2 8}$ \\
\hline
\end{tabular}

Note: Confidence interval of $95 \%$ confidence for the expected average $\left(T s_{m}\right)$, FlexSim $^{\mathrm{TM}}$.

Although previous research recommends assigning a beta distribution to construction activities, when there is not enough data to statistically represent the random behavior of an activity $[51,58]$, it is desirable to evaluate the validity of the model with respect to the assignment of the beta probability distribution type for this particular case study. To do this, based on parameters obtained by the PERT programming tool, different combinations of possible probability distributions were made taking, as example, the normal and uniform betas distributions.

As shown in Table 3, for each of the combinations of possible probabilities, an average duration of the simulation model $\left(\mathrm{Ts}_{\mathrm{mp}}\right)$, was obtained, according to the same methodology used in the previous stages. After the geometric average duration of the 21 possible combinations was calculated, this average duration was finally contrasted with the average duration obtained by the Beta-Beta-Beta distribution combination. From the statistical analysis, by applying the Wilcoxon test, it was shown that independent of

$16^{\text {th }}$ LACCEI International Multi-Conference for Engineering, Education, and Technology: "Innovation in Education and 
the different combinations of probability distributions obtained and based on discrete simulation, there are no statistically significant differences with respect to the classical combination obtained from the beta distribution, validating this type of statistical distribution as a useful and simple tool for engineering and process control.

TABLE III

VALIDITY OF THE BETA DISTRIBUTION VERSUS THE DIFFERENT COMBINATIONS OF POSSIBLE PROBABILITY DISTRIBUTIONS

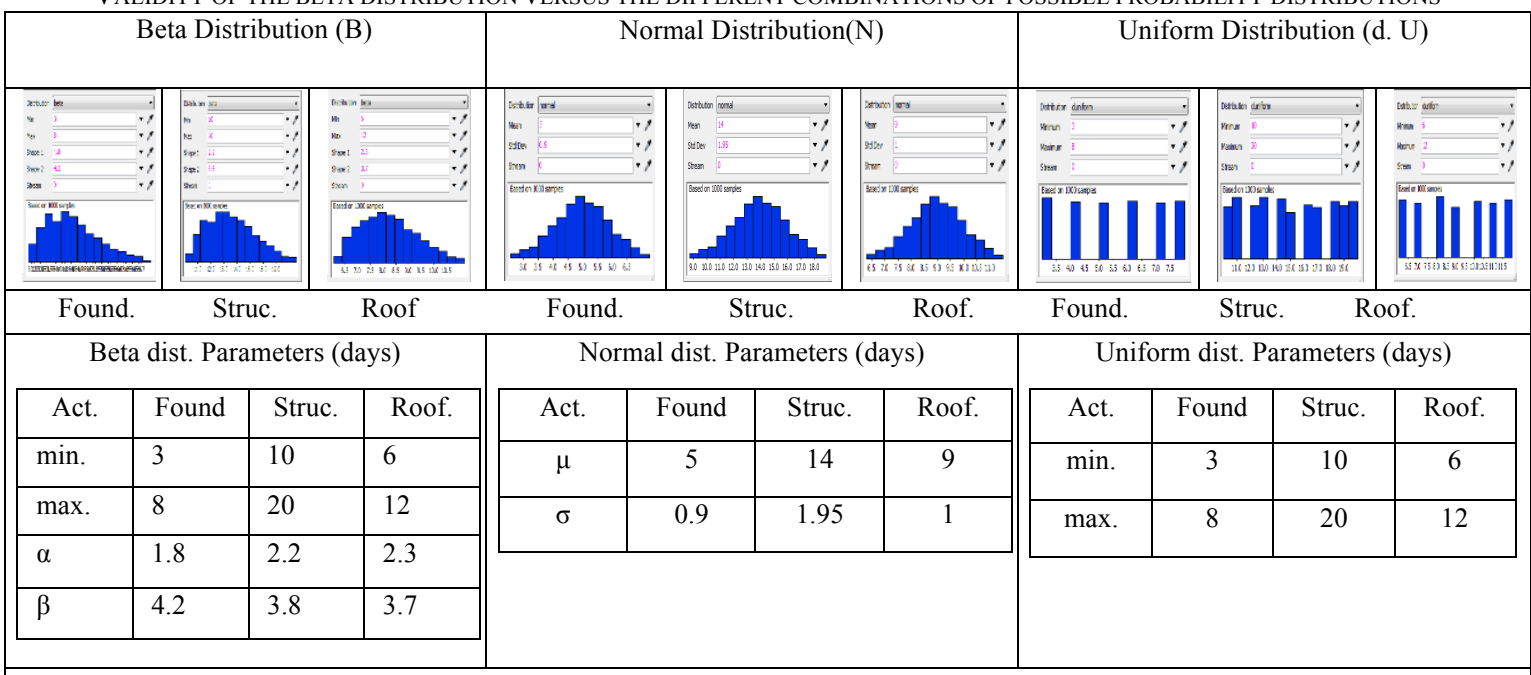

\section{Distribution Combination}

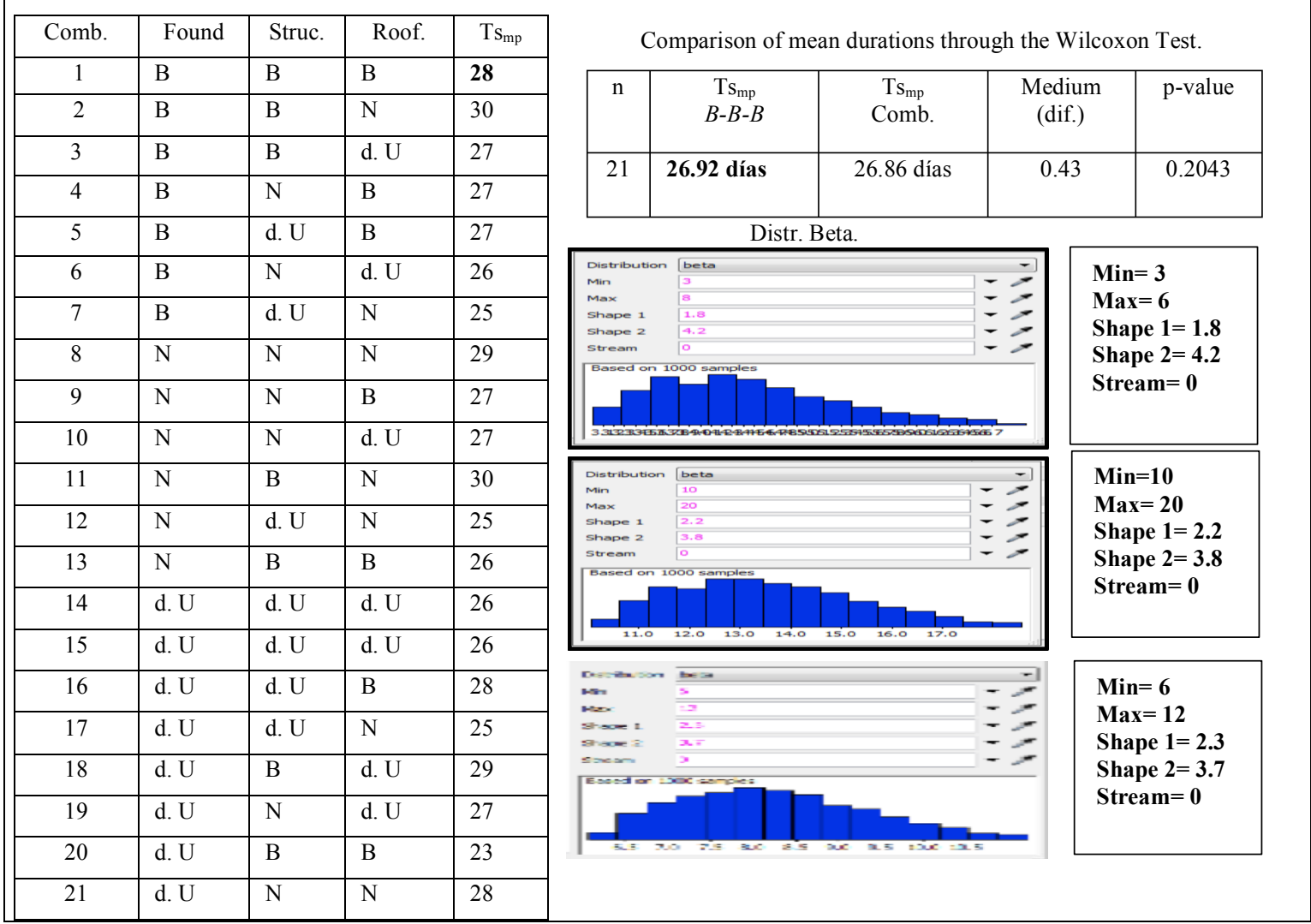

Note: Comparison made with the Wilcoxon test with 5\% significance (InfoStat).

\section{D. $3 D$ visualization}

An important part in the field of operations simulation in construction has been the ability to visualize threedimensional animations of the processes. The visualization of simulated construction operations in 3D format can significantly help to establish the credibility of the simulation models [43]. 
For the constructive process under study, the virtual environment and real-time monitoring of FlexSim ${ }^{\mathrm{TM}}$ software were used to verify the model, where the external tool of Google SketchUp ${ }^{\mathrm{TM}}$ was used for constructing and importing entities used in the subsequent visualization in $3 \mathrm{D}$ format.

Figure 9 shows the construction and subsequent importation of building system entities from Google SketchUp ${ }^{\mathrm{TM}}$ to FlexSim ${ }^{\mathrm{TM}}$, using $3 \mathrm{D}$ graphic exchange file formats .dae; compatible with both software.

Finally, the entities were imported and configured to the respective schedule, the model was run in order to observe the virtual result of the constructive operation in Flexsim ${ }^{\mathrm{TM}}$. The result of the graphical interface of the software is presented in Figure 10.

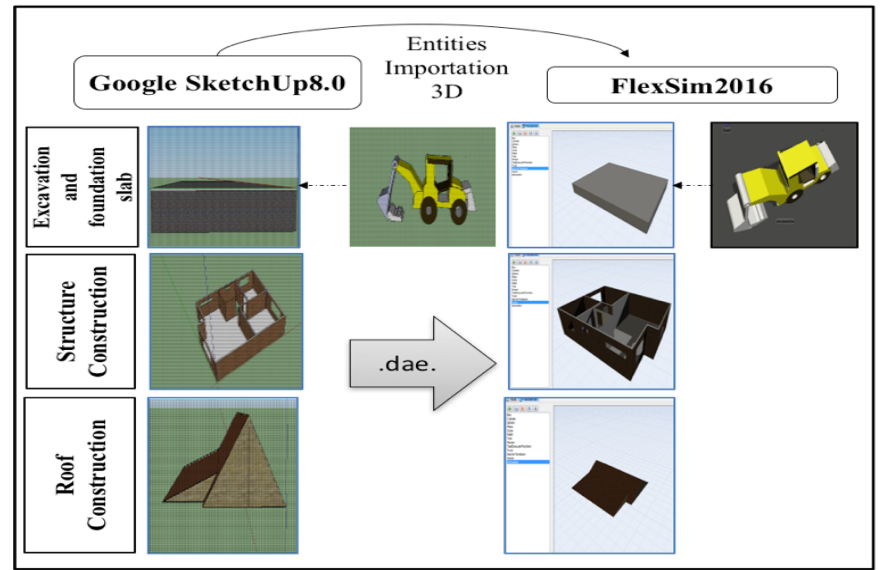

Fig. 9. Construction and import of Google digging entities and resources SketchUp ${ }^{\mathrm{TM}}$ to FlexSim ${ }^{\mathrm{TM}}$

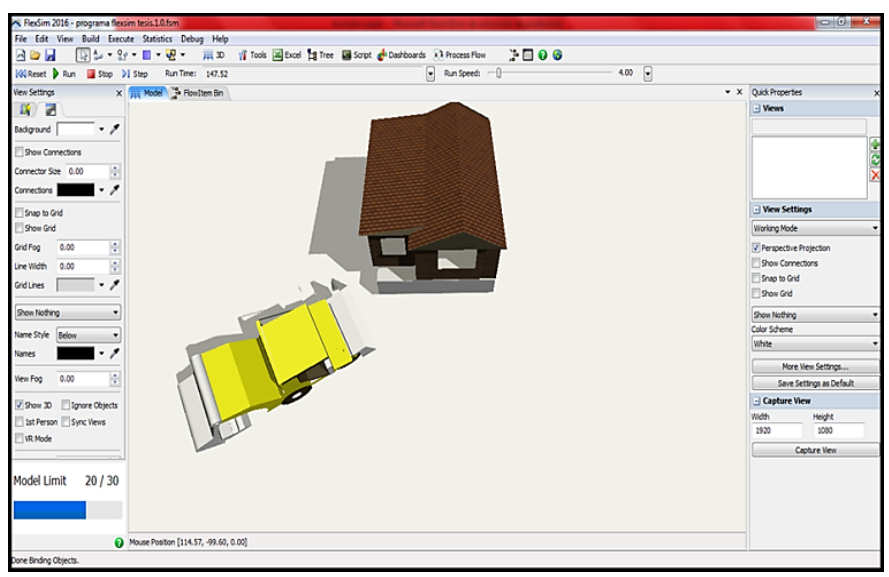

Fig. 10. Graphical interface result of the constructive operation (FlexSim ${ }^{\mathrm{TM}}$ ).

\section{ANALYSIS}

\section{A. Output data}

In order to achieve a graphic description of the durations of the activities, data delivered by the simulation model were analyzed statistically obtaining the corresponding dispersion graphs, frequency histogram and smoothed density. As can be seen in Figure 9, the result of the behavior of the output durations of the simulation model, in each of the activities, tended to approximate a beta distribution.

\section{B. Statistical contrast}

To statistically analyze the durations delivered by the PERT scheduling tool, with respect to the random durations delivered by the discrete simulation model, it was necessary to contrast both scheduling approaches by using the nonparametric Wilcoxon test, with a level of significance of $5 \%$. This statistical test allows the comparison of samples assuming that the origin of these does not conform to a normal distribution (a necessary requirement in other statistical tests such as $t$-student).

Data was divided into 3 groups according to each activity analyzed. For the activity of foundations, 13 samples were considered, 45 for structure and 18 for roofing activity (according to the convergences of the average durations presented in Figure 2). Each data pair was defined assuming for the samples of the PERT model the static value of the expected duration of the activity $\left(\mathrm{Te}_{\mathrm{i}}\right)$, versus the random durations of the simulation model $\left(\mathrm{Ts}_{1}, \mathrm{Ts}_{2}, \ldots, \mathrm{Ts}_{\mathrm{j}}\right)$, as represented in the Table 4.

TABLE IV

StATISTICAl CONTRAST BETWEEN THE PERT MODEL AND THE Discrete SIMULATION MODEL

\begin{tabular}{|c|c|}
\hline $\begin{array}{c}\text { PERT Model } \\
\text { Activity }\end{array}$ & $\begin{array}{c}\text { Simulation Model } \\
\text { Activity }\end{array}$ \\
\hline $\mathrm{Te}_{1}$ & $\mathrm{Ts}_{1}$ \\
\hline $\mathrm{Te}_{2}$ & $\mathrm{Ts}_{2}$ \\
\hline $\mathrm{Te}_{3}$ & $\mathrm{Ts}_{3}$ \\
\hline$\vdots$ & $\vdots$ \\
\hline $\mathrm{Te}_{\mathrm{i}: \mathrm{n}}$ & $\mathrm{Ts}_{\mathrm{j}: \mathrm{n}}$ \\
\hline
\end{tabular}

Note: $\mathrm{Te}_{1}=\mathrm{Te}_{2}=\mathrm{Te}_{3}=\mathrm{Te}_{\mathrm{i}: \mathrm{n}}$ with $\mathrm{i}, \mathrm{j}=1,2,3, \ldots$ to $\mathrm{n}$.

1) Results of the statistical test: Based on the durations obtained through both scheduling approaches (PERT Model versus Discrete Simulation Model), these were compared independently by activity. The modeling hypotheses that were used in this analysis were the following:

$\mathrm{H}_{0}=$ Durations delivered by the PERT programming tool $\left(\mathrm{Te}_{\mathrm{i}}\right)$ are equal in comparison to the durations delivered by the discrete simulation approach $\left(\mathrm{Ts}_{\mathrm{j}}\right)$.

$\mathrm{H}_{\mathrm{a}}=$ Durations delivered by the PERT scheduling tool $\left(\mathrm{Te}_{\mathrm{i}}\right)$ are not equal in comparison to the durations delivered by the discrete simulation approach $\left(\mathrm{Ts}_{\mathrm{j}}\right)$.

From the results obtained by the Wilcoxon test and presented in Table 5, it is concluded that because the p-value for this test was greater than or equal to 0.05 , for each pair of samples in the test, there are no statistically significant differences between the PERT scheduling method and the discrete event simulation approach in analysis.

As it was verified in this case study, the simplified model of discrete simulation obtained equal durations, in relation to the total duration of the construction process (28 days), with respect to the PERT network scheduling tool. This is evidence 
of the quality with which the simulation model represented in a simple way a real system in construction. This being said, it is demonstrated that a simplified and simple approach, based on the simulation of discrete events, can become a useful and valid scheduling tool, capable of being extended and applied by any construction professional, taking as reference their own constructive schedules.

TABLE V

DIFFERENCE OF AVERAGE DURATIONS MODEL PERT (Te) V/s SIMULATION MODEL $\left(\mathrm{Ts}_{\mathrm{m}}\right)$

\begin{tabular}{|c|c|c|c|c|c|c|c|}
\hline \multicolumn{3}{|c|}{ Contrast of Models } & \multicolumn{3}{|c|}{$\begin{array}{c}\text { Average Durations } \\
\text { (days) }\end{array}$} & \multicolumn{2}{|l|}{ ediums } \\
\hline Act. & PERT Model & Simulation Model & $\mathbf{n}$ & $T_{e}$ Act. & $\begin{array}{l}\mathbf{T s}_{\mathrm{m}} \\
\text { Act. }\end{array}$ & $\begin{array}{c}\text { Differences } \\
\sum_{n}^{i ; j=1} \text { dif. }(\text { Tei }-T s j) / n\end{array}$ & p-value \\
\hline A & Foundations $\left(\mathrm{Te}_{\mathrm{i}}\right)$ & Foundations $\left(\mathrm{Ts}_{\mathrm{j}}\right)$ & 13 & 4.6 & 4.70 & -0.10 & 0.8618 \\
\hline B & Structure $\left(\mathrm{Te}_{\mathrm{i}}\right)$ & Structure $\left(\mathrm{Ts}_{\mathrm{j}}\right)$ & 45 & 13.6 & 14.00 & -0.40 & 0.2404 \\
\hline $\mathrm{C}$ & $\operatorname{Roof}\left(\mathrm{Te}_{\mathrm{i}}\right)$ & $\operatorname{Roof}\left(T s_{j}\right)$ & 18 & 8.33 & 8.26 & 0.07 & 0.1744 \\
\hline
\end{tabular}

\section{CONCLUSIONS}

From the exhaustive statistical analysis for each objective activity in this case study, it is concluded that the scheduling approach based on discrete simulation obtained durations equal or similar to the durations provided by the PERT network scheduling method, thus validating the simulation model as a feasible tool for simplified scheduling of a project under construction.

The scheduling approach based on DES allowed obtaining values that were adjusted to the measurements obtained in the field, by including the variability in the duration of the processes (stochastic), unlike other deterministic scheduling techniques.

In addition, the present DES-based scheduling can be easily understood and applied by any construction professional, simply using its own sequence of critical activities, and thereby helping to reduce the uncertainty associated with the completion times of the activities.

Finally, the schedule developed in this research can be considered as a valid management tool, simple to implement and capable of addressing the effects of the variability of construction processes, by including them in a stochastic but simplified analysis of the activities.

\section{ACKNOWLEDGMENT}

This work was partially supported by the Chilean National Commission for Scientific and Technological Research (CONICYT) under grant No.1171108/Fondecyt Regular.

\section{REFERENCES}

[1] Fishman, G. (2013). Discrete-event simulation: modeling, programming, and analysis. Springer Science \& Business Media.

[2] Gómez C., A., Quintana, N. \& Ávila D. J. O. (2014). Simulación de eventos discretos y líneas de balance, aplicadas al mejoramiento del proceso constructivo de la cimentación de un edificio. Ingeniería y Ciencias, 11(21), 157-175.

[3] Serpell, A. \& Alarcón, L. (2003). Planificación y control de proyectos. 2da Ed., Editorial Universidad Católica de Chile: Santiago.
[4] Echeverry, D., Páez, H., \& Mesa, H. (2008). Simulación digital de procesos de construcción de estructura en concreto: casos de estudio práctico en Bogotá, Revista Ing. de construcción, 23(2), 64-71.

[5] González, V., Alarcón, L. F., \& Yiu, T. W. (2013). Integrated methodology to design and manage work-in-process buffers in repetitive building projects. Journal of the Operational Research Society, 64(8), 1182-1193.

[6] Baccarini, D. (1996). The Concept of Project Complexity-a review. International Journal of Project Management, 14(4), pp. 201-204.

[7] Hopp, W. \& Spearman M. (1998), Factory Physics, Mc Graw Hill, Second Edition.

[8] González, V. \& Alarcón, F. (2003). Buffer de programación: Una estrategia complementaria para reducir la variabilidad en los procesos de construcción. Revista Ing. de Construcción, PUC, pp. 109-119.

[9] Li, S., Jia, Y., \& Wang, J. (2012). A discrete-event simulation approach with multiple-comparison procedure for stochastic resource-constrained project scheduling. The International Journal of Advanced Manufacturing Technology, 63(1), 65-76.

[10] Aspray, W. (1990). John Von Neumann and the Origins of Modern Computing, Massachusetts, The MIT Press. pp. 110-113.

[11] Banks J., Carson J.S., Nelson B.L. (1996). Discrete-Event System Simulation, (2da ed.), Prentice-Hall, New Jersey.

[12] Coss Bu, R. (2003). Simulación: Un enfoque práctico, México: Limusa.

[13] Emshoff, J. R. \& Sisson, R. L. (1970). Design and Use of Computer Simulation Models. Macmillan, New York, N.Y.

[14] Pritsker, A. A. B. (1986). Introduction to Simulation and Slam II. Systems Publishing Corporation, West Lafayette, Indiana.

[15] Chapman, R.M. (2000). Mission-Oriented Conceptual Modeling Framework for Distributed Mission Training, Proceedings of the Fall Simulation Interoperability Workshop.

[16] Shannon, R. E. (1998). Introduction to the art and science of simulation, Proceedings of the 30th conference on Winter simulation, Washington, D.C., USA

[17] McHaney, R. (1991). Computer Simulation - A Practical Perspective, Academic Press. New York.

[18] Misra, J. (1986). Distributed discrete-event simulation. $A C M$ Computing Surveys (CSUR), 18(1), 39-65.

[19] Fujimoto, R. M. (1990). Parallel discrete event simulation. Communications of the ACM, 33(10), 30-53.

[20] Kelton, W. D., Sadowski, R. P., \& Sturrock, D. T. (1996). Simulación con sofware Arena, 4nd ed., McGrawHill, New York, NY.

[21] Law, A. M. \& Kelton, W. D. (2000). Simulation modeling and analysis. Boston: McGraw-Hill.

[22] Kirmizialtin, S., Hennelly, S. P., Schug, A., Onuchic, J. N., \& Sanbonmatsu, K. Y. (2015). Integrating molecular dynamics simulations with chemical probing experiments using SHAPE-FIT. Methods in Enzymology, 553, 215-234.

$16^{\text {th }}$ LACCEI International Multi-Conference for Engineering, Education, and Technology: "Innovation in Education and 
[23] Araújo, A. M., Armando, L. R, \& Maurílio, J. D. (2009). Simulación de la Producción de Energía Eléctrica con Aerogeneradores de Pequeño Tamaño, Información Tecnológica, 20(3), pp. 37-44.

[24] Chasalevris, A., Dohnalb, F. (2015). A journal bearing with variable geometry for the suppression of vibrations in rotating shafts: Simulation, design, construction and experiment. Mechanical Systems and Signal Processing, 52-53, 506-528.

[25] Zeigler, B., Tag Gon Kim \& Praehofer, H. (2000). Theory of Modeling and Simulation, (2a ed.), New York: Academic Press.

[26] Gómez C, A. (2010). Simulación de procesos constructivos. Revista ingeniería de construcción, 25(1), 121-141.

[27] Cullingford, G., Mawdesley, M. J. \& Davies, P. 1979. Some experiences with computer based games in civil engineering teaching, Computer \& Education, 3(3), pp. 159-164.

[28] Forcael, E., Glagola, C. \& González, V. (2012). Incorporation of Computer Simulations into Teaching Linear Scheduling Techniques. $J$. Prof. Issues Eng. Educ. Pract. 138(1), 21-30.

[29] Nikolic, D., Jaruhar, S., \& Messner, J. I. (2009). An Educational Simulation in Construction: The Virtual Construction Simulator, Proceedings of the 2009 ASCE International Workshop on Computing in Civil Engineering, Austin, Texas, pp. 633-642.

[30] González, V.; Orozco F.; Senior B.; Ingle J.; Forcael E.; and Alarcón L. F. (2015). LEBSCO: Lean-Based Simulation Game for Construction Management Classrooms. Journal of Professional Issues in Engineering Education and Practice, 141 (4).

[31] Sacks, R., Esquenazi, A. \& Goldin, M. (2007). LEAPCON: Simulation of lean construction of high-rise apartment buildings. En Journal of Construction Engineering and Management, 133(7).

[32] Shawki, K. M., Kilani, K. \& Gomaa, M. A. (2015). Analysis of earthmoving systems using discrete-event simulation, Alexandria Engineering Journal, 54(3), pp. 533-540.

[33] AbouRizk S. M. (2013). Innovations in tunneling construction management: Applications of simulation. In Proceedings of the 3rd International Conference on Computational Methods in Tunnelling and Subsurface Engineering. Edification Publishers: Freiburg, BadenWürttemberg, Germany.

[34] Al-Battaineh, H. T., AbouRizk, S. M., Tan, J. \& Fernando, S. (2006). Productivity Simulation during the Planning Phase of the Glencoe tunnel in Calgary, Canada: a case study. Proceedings of Winter Simulation Conference, Monterey, California, USA.

[35] Rahm, T., Scheffer, M., Thewes, M., König, M. \& Duhme, R. (2016). Evaluation of Disturbances in Mechanized Tunneling Using Process Simulation. Computer-Aided Civil and Infrastructure Engineering, 31: pp. 176-192.

[36] Molina, D., Quesada, A., Febles, Y. A. \& Ramos, L. C. (2017). La simulación en el diseño de los sistemas hidráulicos navales. Ingeniería Hidráulica y Ambiental, 38(2), pp. 29-43.

[37] Hernández, M., A., García S., A., \& Valdés V., J. (2017). Modelo de simulación para estimar la sobrerresistencia a flexión de elementos de concreto. DYNA, 84(200), pp. 112-120.

[38] Halpin, D. W. \& Riggs, L. S. (1992). Planning and analysis of construction operations. New York: John Wiley \& Sons.

[39] Izquierdo, L. (2014). Introducción a la programación orientada a objetos. Recuperado en April 2017) desde: http://luis.izqui.org/resources/ProgOrientadaObjetos.pdf

[40] AbouRizk, S.M. \& Mohamed, Y. (2000). Symphony: An integrated environment for construction simulation. Proceedings, Winter Simulation Conference, Orlando, FL, USA, pp. 1907-1914.

[41] AbouRizk, S. M., Ekyalimpa, R. \& Newstead, S. (2016). Symphony: a next generation simulation modelling environment for the construction domain. Journal of Simulation, 10(3), pp. 207-215.

[42] Liu, H., Altaf, M. S., Lei, Z., Lu, M., \& Al-Hussein, M. (2015). Automated production planning in panelized construction enabled by integrating discrete-event simulation and BIM. In 5th International/11th Construction Specialty Conference, pp. 8-10.

[43] Kamat, V. \& Martinez, J. (2008). Software mechanisms for extensible and scalable 3D visualization of construction operations. Journal of Advances in Engineering Software, 39(8).
[44] Hajjar, D., \& AbouRizk, S. (2002). Unified modeling methodology for construction simulation, Journal of Construction Engineering and Management, 128(2), 174-185.

[45] Sarhan, S. \& Fox, A. (2013). Barriers to Implementing Lean Construction in the UK Construction Industry. Faculty of Science and Technology, University of Plymouth, UK.

[46] Fischer, M., Haymaker, J., \& Liston, K. (2003). Benefits Of 3D And 4D Models For Facility Managers And AEC Service Providers. 4D CAD And Visualization In Construction. Stanford.

[47] Forcael, E., González, V., Orozco, F., Opazo, A., Suazo, A., and Aránguiz, P. (2015). "Application of Problem-Based Learning to Teaching the Critical Path Method". Journal of Professional Issues in Engineering Education and Practices, 141(2)

[48] Agyei, W. (2015). Project planning and scheduling using PERT and CPM Techniques with linear programming, International Journal of Scientific \& Technology Research, 4(8), pp. 2277-8616.

[49] Moitra, S.D. (1990). Skwness and the beta distribution. J.Opl.Res.Soc., 41(10), pp. 953-961.

[50] Córdoba, E. (2008). Análisis y medición de incertidumbre en redes de actividades. Ingenierías, 11(39).

[51] AbouRizk, S. M. \& Halpin, D. (1990). Probabilistic Simulation Studies for Repetitive Construction Processes, Journal of Construction Engineering and Management, 116(4), 575-594.

[52] Waleed Mahfouz M. A. Youssef, Karim M. M. El-Dash, Osman M. O. Ramadan. (2013). Construction Activities Duration Patterns in the Middle East, International Journal of Construction Engineering and Management, 2(4), pp. 122-135.

[53] Koskela, L. (1992). Application of the New Production Philosophy to Construction. Stanford University, CA: CIFE.

[54] Koskela, L. (2000). An Exploration Towards a Production Theory and its Application to Construction. Ph D Dissertation, VTT Building Technology, Helsinki University of Technology, Espoo, Finland.

[55] Serpell, A., Venturi, A. y Contreras, J. (1995). Characterization of Waste in Building Construction Projects. Alarcón, L. F. (ed), Lean Construction, A.A. Balkema, The Netherlands, 497 pp.

[56] Bennet, B. S. (1995)."Simulation Fundamentals", Prentice Hall.

[57] Candia, B. R. \& Caiozzi, A. G. (2005). Intervalos de Confianza, Revista médica de Chile, 133(9), pp. 1111-1115.

[58] AbouRizk, S. M., Halpin, D. W. \& Wilson, J. R. (1994). Visual Interactive Fitting of Beta Distributions, Journal of Construction Engineering and Management, 117 (4), 589-605.

$1^{\text {th }}$ LACCEI International Multi-Conference for Engineering, Education, and Technology: "Innovation in Education and 